\title{
A simplified approach to stakeholder engagement in natural resource management: the Five-Feature Framework
}

\author{
Jared L. Talley $^{1,2}$ Jen Schneider $^{2}$ and Eric Lindquist $^{3}$
}

\begin{abstract}
We distill complex frameworks for stakeholder engagement into five main principles that scientists and natural resource managers can use in planning stakeholder engagement efforts. Many natural resource management professionals, including practitioners and scholars, increasingly recognize the need for, and potential benefits of, engaging stakeholders in complex decision-making processes, yet the implementation of these efforts varies wildly, reflecting great methodological and conceptual diversity. Given the dynamic and diverse natural resource management contexts in which engagement occurs and the often significant stakes involved in making decisions about natural resources, we argue that stakeholder engagement would benefit from a theoretical framework that is both agile and robust. To this end, five essential elements of stakeholder engagement are evaluated and organized to form the Five-Feature Framework, thereby providing a functional and approachable platform with which to consider engagement processes. Aside from introducing and developing the Five-Feature Framework, we apply the framework as a measure to evaluate the empirical case study literature involving stakeholder engagement in natural resource management in an effort to better understand the obstacles facing robust and genuine engagement in natural resource management. Our results suggest that the most basic principles of engagement are often absent from stakeholder engagement projects, which confirms the need for a functional framework. The Five-Feature Framework can be used to plan flexible, adaptable, and rigorous engagement projects in a variety of contexts and with teams that have varying backgrounds and experience. By virtue of its simplicity and functionality, the framework demystifies stakeholder engagement in order to help natural resource professionals build opportunities for collaborative decision-making and integrate citizen values and knowledge into complex management issues.
\end{abstract}

Key Words: Five-Feature Framework; natural resource management; stakeholder engagement

\section{INTRODUCTION}

The natural resource management and public policy literature recommends the inclusion of stakeholders and their interests in decision-making and planning processes, which suggests that stakeholder inclusion contributes to, or increases the likelihood of, better decision-making, increased social learning, and community support for project outcomes (Freeman 1983, Maak 2007, Johnson et al. 2012, Caves et al. 2013, Knapp et al. 2014). Furthermore, stakeholder engagement (SE) (see Defining stakeholder engagement) is increasingly mandated across the spectrum of natural resource management agencies, which requires documented interactions at various stages in the decision process (Brody et al. 2003).

Although increasingly recommended and practiced, there is a disparity in the natural resource management literature between theoretical papers that argue for rigorous SE efforts and empirical case studies that represent on-the-ground SE practices. For example, an oft-cited and vigorous theoretical framework appears in the work of Reed (2008), yet many of the published natural resource management case studies meet only a few of Reed's standards and often appear to do so haphazardly or opportunistically. We present a meta-analysis of this case study literature by identifying those areas where the gap between theory and practice is most apparent. The current literature and our own experiences with stakeholder engagement help to interpret this discrepancy and are used to argue that the wide variety of natural resource management contexts in which SE happens requires a modified framework that is more flexible and accessible than Reed's while maintaining its theoretical rigor.
Generally, we both reframe and simplify Reed's robust stakeholder engagement framework in order to make it more practicable across a broad range of contexts and approachable for practitioners from diverse backgrounds. To this end, we modestly contribute to theory and practice in two ways. First, this study adds to our understanding of the "stakeholder engagement " concept in natural resource management and where the application of SE faces challenges in meeting theoretical benchmarks. Second, we suggest that the framework developed here to measure existing stakeholder engagement - the FiveFeature Framework - can be used to guide future engagements, thereby creating opportunities for cross-comparison studies as well as a foundation for the consistent and methodological application of SE.

\section{DEFINING STAKEHOLDER ENGAGEMENT}

From a critical perspective, the term "stakeholder engagement" is a constructed and contested concept that refers to a wide range of practices that vary according to context. Stakeholder engagement, in the natural resource management context, most often refers to the participation of stakeholders in planning or decision-making efforts in order to integrate their knowledge and values with a particular project's more specialized knowledge and purpose. In turn, "stakeholders" are often broadly defined as those people who are affected by or can affect a decision (following from Freeman 1983), and range from the "average" citizen to groups of highly interested or invested decision-makers. Furthermore, SE facilitators range from academics and environmental consultants to agricultural extension specialists

${ }^{1}$ Department of Philosophy, Michigan State University, ${ }^{2}$ School of Public Service, Boise State University, ${ }^{3}$ Public Policy Research Center, Boise State University 
and government employees, each operating from varied methodologies with often equally varied results. Stakeholder engagement in natural resource management runs the spectrum from very large multinational and multiyear projects (see Partidário et al. 2008, Kidd and McGowan 2013) to local, tightly focused projects (see Knapp et al. 2014, Krasny and Delia 2014) that span vast geographic, political, and cultural scales. In sum, stakeholder engagement initiatives occur across a very diverse range of project scopes and scales, can include a broad range of stakeholders, and are carried out by a diverse set of managers, facilitators, experts, and nonexperts - experienced and inexperienced alike.

Additionally, stakeholder engagement has come to enjoy significant cachet across these many contexts as a sort of "best practice" for planning and decision-making, primarily because it is believed to be both more effective and democratic than topdown, managerialist approaches (Wagenet and Pfeffer 2007, Butler and Adamowski 2015, Decker et al. 2015). Many scholars have argued that integrating stakeholders' knowledge and values in decision-making scenarios ostensibly leads to improved governance and accountability (e.g., Koontz and Thomas 2006, Wagenet and Pfeffer 2007). Others have argued that such claims have not been vigorously tested, and there are divergent views regarding the value and efficacy of stakeholder involvement (e.g., Koontz and Thomas 2006, Powell and Colin 2008, Allen et al. 2013). Other scholars have recognized that the concept of stakeholder engagement itself is conceptually slippery and contextdependent (Freeman 1999, Jones and Wicks 1999, Noland and Phillips 2010). Yet SE has nonetheless emerged as a normative value for those engaged in natural resource management, supported by the practice being institutionalized, albeit in a variety of forms, through requirements in grant-awarding processes and administrative protocols for government agencies in the Unites States and abroad.

The ubiquitous nature of SE belies the disparity between theory and practice as it is difficult to develop a one-size-fits-all practice that captures the critical components of SE while respecting SE's instrumental and normative requirements. Difficult as this may be, stakeholder engagements across various contexts are not without similarities; thus, general criteria and features of engagement can be developed and refined, thereby providing a stable platform to guide SE efforts. In the following section, we use Reed's (2008) SE framework to develop an instrument that is simple enough to evaluate the broad, diverse set of existing case studies that claim to use stakeholder engagement, yet is sophisticated enough to capture the apparent similarities and requirements for robust SE across varying contexts.

\section{DEVELOPING A METRIC FOR ENGAGEMENT}

Stakeholder participation in natural resource decision-making processes is not a novel concept. Reed's (2008) review of stakeholder participation in natural resource management provides an extensive evaluation of the concept, grounded in the participatory management literature and tracing its roots to Arnstein's (1969) "ladder of participation." In his review, Reed develops a series of eight practices for conducting successful stakeholder engagement: (1) provide a culture of empowerment, trust, and equity, (2) include stakeholders as soon as possible, (3) systematically represent stakeholders, (4) clearly define objectives,
(5) use contextually relevant methods, (6) skillfully facilitate engagement processes, (7) integrate local and scientific knowledge, and (8) institutionalize participation. Ultimately, Reed argues that stakeholder engagement should be approached with an emphasis on participation instead of merely to secure social license or reduce conflict, and the eight steps reflect the engagement literature's commitment to democratic decisionmaking processes (Smith and McDonough 2001, Wagenet and Pfeffer 2007, Butler and Adamowski 2015).

Reed's eight characteristics provide a decisive guide for how best to effectively engage stakeholders in natural resource management, yet an initial literature review revealed that few practitioners were meaningfully engaging theoretical frameworks such as Reed's. Although some of the cases intermittently described some feature of Reed's prescriptions as relevant or appropriate, it was clear that few were applying or systematically adopting any framework whatsoever, and it was even clearer that the essential features of SE were either being overlooked or underappreciated. Given the range of SE contexts presented in the case study literature and the infrequent description of common principles, a measure of SE was developed by condensing Reed's framework into essential and recognizable features in order to adequately make comparisons across cases. As a result, the Five-Feature Framework we present represents a distillation and simplification of Reed's framework that endeavors to retain the most significant elements of theoretically robust SE while providing a metric with which to measure SE efforts. The recognition that this developed measure could be of use in guiding SE as well as measuring the success of SE provides the normative dimension of this work. Each of the five features is examined in detail in the following sections.

\section{Feature 1: Set clear objectives}

At the outset of any SE, regardless of context, the objectives of the engagement process need to be clearly articulated, including justification for the inclusion of stakeholders (Stringer et al. 2006, Gopnik et al. 2012, Rowe and Frewer 2000). There are many possible objectives for engagement processes, including characterizing stakeholder values, integrating stakeholder knowledge, and involving stakeholders in decision-making. Not every project need meet each of these objectives, but research suggests that having a clearly stated objective (1) indicates thoughtfulness about what the outcomes of the process should be, and (2) allows organizers to plan ahead with regard to the other features of SE-in particular, how to ensure systematic representation, choose a relevant methodology, and ensure meaningful co-ownership of the process (Lachapelle et al. 2003, Kemp et al. 2005, Powell and Colin 2008, Gopnik et al. 2012).

Objectives can often remain implicit or unstated, which serves to confuse and complicate the engagement. If the SE does not have clearly articulated expectations, it is likely that the other features - either ours or Reed's - will be difficult to suitably implement since, for example, choosing methodologies and facilitation details relies on desired outcomes. Ideally, objective-setting is done in consultation with stakeholders; engagement scenarios that begin with imprecise or unidentified goals, emotionally charged participants, and/or expectations for long-term engagement should seek to engage stakeholders in the process of determining objectives as a shared activity in order to address 
conflicts, communication problems, and other obstacles in advance (Chess and Purcell 1999, Larson et al. 2010). It should be noted that in many SE contexts, objectives are decided in advance (e.g., government agencies that have mandated SE), in which stakeholders may not be brought in early, unless so mandated, and opportunities to share ownership of the project may take more time and resources.

\section{Feature 2: Systematically represent stakeholders}

The second step - systematically represent stakeholders-was retained from Reed's original framework. Careful consideration of who is engaged, including consideration of who is excluded, is a fundamental element of SE, regardless of context, and in the conceptual SE literature, much attention is paid to the complexities of stakeholder identification and representation (Mitchell et al. 1997, Stringer et al. 2006, Reed et al. 2009). What counts as "representation," however, should proceed from the stated objective(s) of the SE-how to operationalize representativeness depends largely on context and project goals. Research shows that broader participation, including the identification and inclusion of stakeholders who are relevant to the objectives and context of the participatory process, can improve both the effectiveness and efficiency of the engagement itself as well as the outputs and outcomes of the process (Grimble and Wellard 1997, Kellert et al. 2000). Deciding who is involved should be done with great care and in a systematic and reflexive fashion.

Certain voices or perspectives will always be excluded in SE because it is nearly impossible to ensure total representation in practical settings. Stakeholder engagement organizers should therefore make every effort to clearly articulate reasons for why some stakeholders are included and others are not. If stakeholders are chosen for convenience, influence, or political expediency, such assumptions should be made explicit, and SE facilitators should acknowledge the resulting limitations. Such acknowledgments are rarely made in the case study literature. Ideally, organizers should avoid marginalizing groups and may need to think carefully and creatively about how to meaningfully engage such groups (Tompkins and Adger 2004, Prell et al. 2009). From a normative perspective, certain stakeholders may have a legitimate basis for being represented that goes beyond instrumental considerations, including claims of morality, property rights, social equity, or elevated risks (Mitchell et al. 1997, Parkins and Mitchell 2005). We acknowledge again, however, that some contexts may preclude broad representation; at a minimum, we encourage scholars and practitioners to articulate these limitations and reflect on their consequences.

\section{Feature 3: Use relevant methodologies}

If methodologies flow logically and intentionally from objectives and accommodate the capabilities of identified stakeholders, they likely meet Reed's injunction to be contextually relevant as well as his prescription for skilled facilitation. Some methodologies, such as public meetings or focus groups, require a different type of expertise than other methods, such as surveys and elite interviews. Skilled facilitation should track the determined methodologies, and as such, it was subsumed under our third feature. However, the question of methodological expertise poses challenges for many who are charged with doing SE, as evaluated in the following sections.
Additionally, methods for SE need to be contextually appropriate and account for inherent complexity and obstacles to participation (Rowe and Frewer 2000, Allen et al. 2013, Caves et al. 2013). Participation methods are many and diverse, including (but not limited to) formal meetings and forums, interviews, social network mapping, surveys, citizen action boards, and interactive modeling (Hood et al. 2010), and it is important to choose methodologies that increase the scope of representation rather than limit it. For example, an engagement may try to be broadly representative by meeting with men and women from a community together, when in fact, holding meetings that are segregated by gender may allow women to say things they might not normally say around the men in their communities. Similarly, it may be necessary to use a translator to overcome language and cultural barriers (Stringer et al. 2006, Reed et al. 2009).

\section{Feature 4: Create opportunities for co-ownership}

The fourth and fifth features in the Five-Feature Framework endeavor to capture the most challenging and normative of Reed's eight features. Reed's first feature argues for a culture of empowerment, trust, and equity, and his second argues that stakeholders be involved as early as possible. The seventh feature requires that local and scientific knowledge be integrated, and the eighth feature prescribes that participation be institutionalized. The four features were distilled into two that are both essential and flexible-opportunities for co-ownership be created whenever possible (Feature 4), and that there be some degree of reflexivity and agility built into SE processes (Feature 5) - and are more easily measured as per the initial purpose of developing a metric for SE.

The term "co-ownership" was chosen rather than the institutionalization of participation because the range of SE contexts allows some efforts to be short-term, provisional, and lacking resources to fully embed in traditional institutions. However-and regardless of context - all SE efforts should be marked by minimal degrees of ownership over the process and outcomes, thus prompting the "co-ownership" label. Developing processes where SE organizers, facilitators, and stakeholders coown elements of the project encourages all groups to think about ways to operationalize empowerment, trust, and equity. Furthermore, not all natural resource management contexts require the integration of local and scientific knowledge. Given the range of SE contexts and objects, many efforts may engage individual stakeholder groups for purposes other than knowledge integration. This does not suggest that these are not meaningful SE efforts since these narrow stakeholder groups are still able to be systematically and purposefully chosen. These considerations prompted the condensing of Reed's features into our five, erring on the side of developing a measure that accommodates a range of contexts while maintaining the essential features of SE.

The prescription to create opportunities for co-ownership, however, is not obviously simple. Co-ownership over the process can happen in degrees and should be minimally marked by authentic two-way dialogue and ideally by the opportunity to genuinely influence decision-making and process outcomes (Korsgaard et al. 1995, Rowe and Frewer 2000, Powell and Colin, 2008, Soste et al. 2015). While it may not always be possible for stakeholders to have definitive decision-making authority in natural resource management scenarios, SE organizers can aim 
Table 1. Journals analyzed and search results as of May 2015.

\begin{tabular}{lccc}
\hline \hline Journal title & Stakeholder/engagement results & "Stakeholder engagement" results & Case studies \\
\hline Journal of Environmental Management & 202 & 66 & 30 \\
Environmental Management & 123 & 33 & 17 \\
Journal of Environmental Planning and Management & 331 & 40 & 14 \\
Society and Natural Resources & 397 & 22 & 9 \\
Ecology and Society & 268 & 13 & 5 \\
Total & 1321 & 170 & 79 \\
\hline
\end{tabular}

to build in opportunities for self-expression, feedback, and critique. Robust engagements provide stakeholders the opportunities to reflect upon the process, affect the engagement's direction, and communicate iteratively with managers such that there is a meaningful feedback loop between participants and facilitators. This shared responsibility for the efficacy of the project is a key component of the democratic ideals in SE (Webler et al. 1995, Innes and Booher 2004, O'Faircheallaigh 2010, Soste et al. 2015). Although the methods of participation may vary across different contexts, stakeholder input should legitimately affect the objectives, processes, and/or outcomes of the process in order to foster co-ownership.

\section{Feature 5: Reflect on processes and outcomes}

We argue that an essential element of SE is that SE practitioners be iteratively reflexive and intentional about the choices they make. For example, if a well-intentioned SE project initially engages only a narrow stakeholder group (especially if the group is generally perceived to unduly influence key aspects of management), and does not engage with those groups that may challenge the process, those that have legitimate rights to the process, or other concerned citizens, the SE effort risks losing legitimacy, and trust and empowerment may become difficult goals to achieve. In this case, organizers may halt the process until stakeholders from these groups can be identified and engaged, thereby ensuring a dedication to robust outcomes and a commitment to fundamental SE norms. The SE process, therefore, needs to be iterative in order to address shortcomings and obstacles, and as such, facilitators need to build in opportunities for meaningful self-reflection and participant feedback. Stakeholder feedback about the engagement process, facilitator reflection on stakeholder representation, engagement methods, and co-ownership opportunities_including assessing barriers to meeting these standards - should feed back into the process in order to guide ongoing and future efforts (Keen and Mahanty 2006). This process of reflexivity is important in order to ensure that these minimal standards are being met and to evaluate the efficacy of the engagement. A facilitator's reflection allows a pause in momentum such that objectives, identification, methods, and co-ownership can be re-evaluated in order to maintain authentic forms of engagement.

In sum, we believe that one of the strengths of stakeholder engagement as a concept is its adaptability across vastly different scenarios and contexts. These five features provide a collectively functional measure with which to measure and compare SE efforts in the case study literature and are flexible and straightforward enough to guide future robust SE efforts. However, a systematic review of case studies in the natural resource management literature suggests that while SE efforts often have some of these characteristics, it is rare for them to have all or even most. In particular, the most challenging of the features-systematic representation, co-ownership, and even engagement reflexivityare often missing from SE efforts, at least as they are portrayed in published case studies.

\section{METHODS}

Before evaluating the normative claims of the Five-Feature Framework, we describe how this framework was systematically used to analyze existing SE case studies in the natural resource management literature. Initial online searches for journals included multiple combinations of the terms "environment," "natural resources," "management," and "policy." Searches focused on journals that publish a wide variety of natural resource management cases rather than those that focus on one resource area only (such as water resource management; future work may focus on how particular resource areas or disciplines construct or theorize the stakeholder concept). From this list, we further focused our search by identifying the journals that returned results after searching for both the terms "stakeholder" and "engagement," and that were restricted only by date parameters embedded in the search engines themselves. This narrowed the list of journals to five, which represented 1321 articles. This further supported the claim that natural resource management is increasingly incorporating stakeholder engagement as a key concept or approach. This list of articles was further reduced by looking specifically for the coupled phrase "stakeholder engagement" in order to target those cases that addressed SE specifically as a key concept or set of practices. The total number of articles returned from the combined "stakeholder engagement" search was 170 (Table 1).

Lastly, the data were reduced by eliminating articles that did not focus specifically on applied stakeholder engagement. These included articles that focused on the theoretical conceptualization of SE rather than the application (such as Reed's) or that mentioned stakeholder engagement only in passing or in a bibliography. The final number of case studies examined in the natural resource management literature that meaningfully discussed the practice of stakeholder engagement was 79 .

Each of the 79 articles was read and evaluated with a simple manual coding process of noting when one of the five essential features of SE was present. It is important to note that the articles were rated only on whether some mention of one of the five features was made by assigning a score of " 1 " or " 0 " (" 1 " for present, " 0 " for absent), which does not evaluate the quality of the feature in relation to the engagement. This was done to provide a minimal benchmark of SE under the assumption that if the five 
features were being met (regardless if they were well met), then SE efforts would be meeting minimal requirements that could be refined and qualitatively studied in future projects. To ensure inter-rater reliability, we chose and independently reviewed a random sample of 50 articles from the initial 170, and either rejected the article due to it not being a case study or coded the article with regards to the Five-Feature Framework, then discussed together until we were all in accord.

As described, a qualitative analysis of the 79 articles is beyond the scope of this article. However, it is useful to provide examples from the articles to illustrate how an article received a " 1 " rather than a " 0 " score for each of the five features. This blunt rating system required subjective judgments in some cases, given that authors wrote about varied contexts, operated under different definitions of SE, and had different (and often unstated) objectives. For example, a case study that examined the engagement of modeling experts in creating forest management modeling tools received a " 1 " for having a clearly stated objective:

Over a period of three years, the Silvopastoralism program gathered together over twenty livestock and forestry technical agencies, local governments, and teaching and research institutions around a shared objective: to produce technical knowledge on silvopastoralism to improve wooded areas in southern France (Aubron et al. 2013:164).

This statement was marked as addressing Feature 1 (set clear objectives); however, the quote was also the only reference to stakeholder representation in the article. Although the authors mentioned that 20 institutions were represented, there is no discussion of how or why they were chosen, who might have been omitted, and what problems or challenges that might have posed. Thus, while the project itself may have systematically represented stakeholders in practice, it was not possible to tell that from this article. As a result, this case received a " 0 " as a score for Feature 2.

In contrast, an article that reported on an SE effort to develop a sustainability assessment in Europe scored a " 1 " for each of the five features. Their objective was clearly defined: "National teams sought a comprehensive understanding of the drivers for change and their implications for all three dimensions of sustainability (i.e., environment, society, and economy)" (Partidário et al. 2008:147). The organizers performed socio-economic and cultural assessments on its study areas as "...the basis for the selection of stakeholder panel members...each stakeholder panel was intended to be representative of the range of perspectives, and not of particular groups or interests" (Partidário et al. 2008:152). This culminated in a detailed list of stakeholder participants, which included, as a small sample, an unemployed sheep farmer, a drug store and local tourism business owner, the mayor of a Slovakian village, a forester for the UK, and recent migrants to the study areas (Partidário et al. 2008:150). This level of detail regarding representation was unusual in most of the cases reviewed and reflects a commitment to the demands of systematic representation. The methods used by the SE organizers also mapped only to the objectives; a variety of methods, including interviews, questionnaires, document reviews, and meetings guided the stakeholders and organizers in developing the sustainability assessment frameworks (Partidário et al. 2008:150).
The case study also scored a " 1 " for the features of co-ownership and reflexivity, unlike many of the others. Stakeholders in this case were involved in defining and refining objectives in an iterative process, and in some situations actually reformulated assessments altogether, which suggests that co-ownership opportunities were present and taken seriously (Partidário et al. 2008:153, 157). Finally, the case study shows the organizers' reflexivity through descriptions of conflicts that arose and steps that were taken to work past them. For example, some researchers from the interdisciplinary team were explicitly concerned "about whether they could engage stakeholders at all," in which the organizers "provided some training on participatory processes" (Partidário et al. 2008:162). This shows a straightforward reflection on the process, which allowed organizers to confront obstacles and offer solutions during the process in order to better facilitate engagement. This case study explicitly elaborated on the process and outcomes of the SE effort, detailing instances of each of the five features, and thus scored a " 1 " for each.

These examples represent the range of cases the sample contained and help illustrate how coding was completed. The remainder of this article is devoted to the results and a discussion of this metaanalysis and how the five-feature metric developed for this study can be used as a planning tool for a variety of SE efforts.

\section{RESULTS AND DISCUSSION}

Given that SE occurs over a great range of contexts, and given the difficulty of translating these complex details into academic articles, we acknowledge that simple frequency counts of the fivefeature measure provide only a partial picture of how SE is being practiced. Nonetheless, the descriptive statistics displayed in Table 2 highlight some possible successes and deficiencies in current SE efforts. For example, the results for Features 1 and 3 (clear objectives: $91.1 \%$, and relevant methodology: $93.7 \%$ ) suggest that most of the case studies in the sample clearly articulated the purpose of the SE effort and applied a methodology that is clearly mapped onto the objective(s). However, less than half of the case studies $(44.3 \%)$ mentioned how or why particular stakeholders were chosen, which raises significant questions about the representativeness of those efforts and the thought given to inclusion of potentially marginalized groups. Engagement reflexivity showed similar results $(51.9 \%)$, and due to its difficulty and complexity, co-ownership is the predictably lowest score at $32.9 \%$. These results are perhaps unsurprising for a number or reasons, yet are indicative of the challenging nature of sharing process ownership with a diverse group of stakeholders across a range of often challenging contexts.

Table 2. Totals and rates of presence of the five features in the analyzed articles.

\begin{tabular}{ccccc}
\hline $\begin{array}{c}\text { Clear } \\
\text { objectives }\end{array}$ & $\begin{array}{c}\text { Systematic } \\
\text { representation }\end{array}$ & $\begin{array}{c}\text { Relevant } \\
\text { methodology }\end{array}$ & $\begin{array}{c}\text { Co- } \\
\text { ownership }\end{array}$ & $\begin{array}{c}\text { Engagement } \\
\text { reflexivity }\end{array}$ \\
\hline 72 & 35 & 74 & 26 & 41 \\
$91.14 \%$ & $44.30 \%$ & $93.67 \%$ & $32.91 \%$ & $51.90 \%$ \\
\hline
\end{tabular}

\section{Setting clear objectives}

The proclivity of clearly articulated objectives for SE is heartening because it suggests that many SE organizers are thinking in advance about why they are doing SE (or being mandated to do 
so). However, and due to the other scores, merely having a clear objective does not lead to robust SE efforts that meet the democratic goals prescribed in the literature. For example, one could clearly articulate an objective for SE (often an artifact of academic publication) without regard for systematic representation based on values of equity, fairness, or deliberative decisionmaking. Similarly, objectives may be technocratic or unidirectional without attention paid to co-ownership and process reflection. Lastly, clear objectives often preempt relevant methodology; knowing why something is done might suggest how to do it, yet this does not require attention paid to the other more value-laden and challenging features of SE. Thus, clearly articulated objectives are essential, yet insufficient for robust SE.

\section{Systematically representing stakeholders}

At the crux of stakeholder engagement is, necessarily, stakeholders and the identification of participants as such. The ill-attention paid to justifying the inclusion or exclusion of certain groups is disquieting, particularly the lack of discussion regarding which stakeholders were omitted from the SE effort and why. Although the critical and theoretical traditions of SE emphasize this extensively, many case studies either gloss over representation or seem to take it for granted. This may be due to conveniencebased representation because it is much easier to work within one's own networks or with those that are already engaged, or perhaps it is due to the fundamental ambiguity of SE. Many efforts may be labeled as SE, yet due to their tightly circumscribed contexts and mandates requiring certain groups, or for concerns of expedience, are more accurately described as a mere meeting rather than a deliberative engagement. Regardless, organizers should carefully consider those who are and are not engagedespecially when SE is mandated or otherwise constricted-and should clearly articulate the processes of representation.

\section{Using relevant methodologies}

Similar to the first feature of setting clear objectives, many case studies clearly articulated methodologies that were well mapped onto stated objectives. Again, using a relevant methodology does not necessarily preempt consideration for the other more difficult features of systematic representation, co-ownership, and reflexivity. Also, although during coding it seemed apparent that the applied methodology was well suited to the context, it is worth noting that this could be an artifact of the engagement organizer and/or manuscript author presenting the methodology as such, and thus may be an artificial representation of methodological relevance. The level of information regarding the context of the engagement that is necessary to ascertain the relevance of the applied methodology is often not present in academic publications. This does not itself threaten the presented results because the features were measured for presence and not quality, yet it does suggest that engagement scholars need clearly articulate the full context of the engagement (see Defining stakeholder engagement) in order for their audience to appreciate the relative (dis)advantages of their applied methodology. Furthermore, it bears repeating that like objective-setting, relevant methodology is alone insufficient to meet the normative demands of robust SE, and attention needs to paid to the impact that a certain methodology has on facilitating representation, co-ownership, and process-reflection.

\section{Creating opportunities for co-ownership}

The lowest score $(32.9 \%)$ was in the category of co-ownership, which is intuitively unsurprising as this feature presents the greatest challenge for SE organizers because developing SE efforts that have an element of shared design, responsibility, and/or governance requires the willingness to cede some control over processes, outcomes, and the investment of time and resources. Furthermore, not all SE efforts have co-ownership as either an objective (e.g., engaging to characterize stakeholder perceptions) or an achievable reality (e.g., federally mandated procedures laden with political and policy barriers that limit the dispersal of process-ownership). Yet this alone does not diminish the prescription or value of co-ownership, and the creation and nourishment of any opportunity is key if SE is to live up to its expectations for improved governance and expanded democratic representation and involvement.

The recognition that some SE efforts have institutionalized obstacles to co-ownership, particularly those that are dominated by technocratic or mandated approaches, should prompt a careful consideration of the reasons for the SE effort because much SE happens in a sort of one-way or "check-box" kind of engagement (Hamilton 2003, Depoe et al. 2004, Endres 2009). These forms of instrumental stakeholder engagement are often motivated by a perceived need to gain buy-in in order to legitimize a particular project or management practice, and are therefore seen as necessary to avoid conflict and ensure smooth implementation of management decisions (Vigar and Healey 2002). Not being clear about the motivation for SE can create challenges for those working to engage stakeholders. Are stakeholders integrated for democratic ends to improve the quality of resource management, or are they engaged to ensure that managers can proceed with decision-making in an environment with less friction - a sort of "social license" model of engagement? In practice, these two types of engagement may not be so neatly cleaved; we can imagine scenarios in which organizers might move back and forth between aspirational and instrumental motivations within a single project. Furthermore, it seems possible that instrumental models of engagement may have democratic ends, while aspirational models may lead to frustrating dead ends. In contexts where there are strong instrumental pulls on natural resource managers or SE organizers, we argue that it becomes all the more important to integrate opportunities for co-ownership and reflection in order to counter structural forces that support primarily more superficial engagement practices.

\section{Reflecting on processes and outcomes}

Roughly half $(51.9 \%)$ of the examined case studies reflected on processes and outcomes, and even fewer did so in consultation with stakeholders. It is possible that self-reflection is poorly described in the academic literature, perhaps due to an underappreciation for descriptive analysis of self-reflection, yet this lack of meaningful self-reflection suggests that SE organizers may not know which features they are missing or how their processes were impacted as a result of overlooking key characteristics of robust engagement. Furthermore, selfreflection provides opportunities for co-ownership because stakeholders would ideally be involved in reflecting on the apparent successes and deficiencies of SE efforts, and thus provide guidance on how processes might by modified and improved. The pause in momentum allowed by iterative process-reflection allows 
organizers to assess and redress challenges in the implementation of the other four features and provides useful teaching moments that encourage a more realistic approach to SE, its promises, and its perils. Descriptive reflection on the processes and outcomes of $\mathrm{SE}$ in academic publications also helps provide a wealth of knowledge that can motivate future cross-site comparison studies and guide robust future engagements. Given that meaningful reflection can happen independently of many resource constraints, can greatly increase the success of an SE, and is necessary for detailed academic descriptions of SE processes and outcomes, engagement reflexivity should be carefully and specifically considered in all SE efforts.

\section{FIVE-FEATURE FRAMEWORK}

This study is a product of our participation in a large, interdisciplinary team science effort at our own institution that required SE across a variety of contexts. The difficulties and obstacles facing interdisciplinary teams have been well documented, including the challenges of collaborating when team members operate from different epistemologies, use specialized vocabularies, and hold personal values based on divergent worldviews (Ritti 1968, Sands et al. 1990, O'Rourke and Crowley 2013). There may also be uneven team dynamics, wherein the natural sciences occupy a privileged position vis-à-vis experts from the social sciences or humanities (Biagioli 2009). This asymmetry can affect communication patterns or implicit power structures in interdisciplinary teams and can be explicitly expressed in terms of how resources are allocated or teams are managed, especially in cases where different team members have competing operational definitions of SE, how it is done, or what its goals are. In particular, the "social" or "broader impacts" are frequently not well integrated with scientific and technical efforts and may be unaccounted for in project design. Despite this, there is increasing agreement that complex social and environmental problems can rarely be tackled by expertise from one background or discipline alone (McLain and Lee 1996, Saloranta 2001, Bond et al. 2015).

For many of these reasons, our own interdisciplinary team struggled to develop a shared language about SE — what it meant, how it might be implemented across diverse projects and contexts, and how the outcomes of these efforts would be evaluated. It was clear that an uncomplicated tool for SE that was flexible and adaptable to a variety of scenarios was necessary for the team to rigorously and consistently approach SE across projects, and in order to meet a variety of objectives. The Five-Feature Framework had already been developed to perform this analysis of the SE literature and was quickly applied as a planning and evaluation tool to many of our team's SE efforts. Thus, the descriptive tool became a normative one. To this end, we developed a short Five-Feature Framework template with questions that serve as prompts to consider the five essential factors of SE:

\section{Clear objectives}

1. What is the aim of engaging or collaborating with stakeholders for this project?

2. Are you able to co-design these objectives with your stakeholders, and can you use that feedback to adjust the objectives as a result?
Systematic representation

1. Who are you engaging, and why?

2. How do you know this is the "right" set of stakeholders, and is it possible that relevant stakeholders have been excluded?

Relevant methodology

1. How will you engage stakeholders, and can you find examples of how others have used those methods successfully?

2. Do your methods relate to your objectives and accommodate the capabilities of your identified stakeholders?

Co-ownership

1. How have you created opportunities for co-ownership in the engagement process?

2. What kind of balance do you want to strike between directing the process and leaving things open to feedback or change?

\section{Engagement-reflection}

1. How will you know, during the process, if the engagement is working?

2. What opportunities have you created for team members and stakeholders to evaluate the stakeholder process?

These questions have varying relevance across projects but are clear enough to serve as a ready starting point for planning, discussion, reflection, and evaluation of SE, particularly in an interdisciplinary research context. This framework has been well received because it provides a template for those who are new to SE but are personally motivated or required to develop SE efforts with other members of the team. The framework has now been applied across several different natural resource management contexts, including one in which a team of academic scientists needed to engage members of government agencies in the design of climate modeling products, and another in which a team of social scientists wanted to engage nonprofit conservation groups. The framework has been a useful planning and guidance tool for these projects by helping to clarify the objectives for these engagements, explicitly consider difficult questions about representation (who is present, who is not, and why), and design appropriate and relevant methodologies to engage these stakeholders. The Five-Feature Framework provides common ground for discussions about why stakeholders are being engaged, where there is a need for assistance or further planning, and how to know when SE efforts have been successful and met project objectives.

\section{CONCLUSION}

As noted, we have been heavily influenced by the work of Reed (2008) and others who offer theoretical frameworks for conducting theoretically robust SE (see also Rowe and Frewer 2000, Stringer et al. 2006, Powell and Colin 2008, PytlikZillig and Tomkins 2011). These frameworks are both thorough and rigorous, and they should be considered in SE efforts. Yet the results presented suggest that complex frameworks are difficult to translate into practice, especially while retaining the flexibility 
and adaptability that makes SE such a powerful tool. As addressed previously, this is particularly true for management teams that represent diverse disciplinary and professional backgrounds, especially those with divergent objectives for SE. We argue that a more digestible and broadly practicable, yet rigorous, framework is useful as a starting point for judiciously planning and evaluating SE efforts.

Effective stakeholder engagement promises to yield better decision-making, increased social learning, and clearer communication between scientists, managers, and the public at large. The strengths of stakeholder engagement lie in its flexibility and adaptability, yet this also introduces complexity into engaging stakeholders, given conceptual, pragmatic, and institutional challenges. The objective of this analysis is to clarify the concept as it is applied within both the academic and practitioner communities and respond to patterns in the literature on natural resource management. To this end, we have developed the FiveFeature Framework, which consists of clarified objectives, systematic representation, relevant methodology, co-ownership, and engagement reflexivity, and then have applied it to the natural resource management case study literature. Our goal is not to water down SE frameworks or concepts, nor to let natural resource managers or scientists off the hook. Rather, we offer the Five-Feature Framework as a way to usefully guide nascent projects toward more robust planning and assessment of SE efforts. We believe the framework provides an approachable starting point for robust engagement, and perhaps an opportunity to bridge the gap more easily between theory and practice. Ultimately, it is our hope that adopting the framework will help maintain the integrity of the stakeholder engagement concept, allow for comparisons and knowledge-building across cases, and help increase skills and capacities among natural resource managers and scholars.

Responses to this article can be read online at: http://www.ecologyandsociety.org/issues/responses. $\mathrm{php} / 8830$

\section{Acknowledgments:}

This publication was made possible by the NSF Idaho EPSCoR Program and by the National Science Foundation under award number IIA-1301792.

\section{LITERATURE CITED}

Allen, E., C. Kruger, F.-Y. Leung, and J. C. Stephens. 2013. Diverse perceptions of stakeholder engagement within an environmental modeling research team. Journal of Environmental Studies and Sciences 3(3):343-356. http://dx.doi.org/10.1007/ $\underline{\text { s13412-013-0136-X }}$

Arnstein, S. R. 1969. A ladder of citizen participation. Journal of the American Institute of Planners 35(4):216-224. http://dx.doi. org/10.1080/01944366908977225

Aubron, C., G. Guérin, B. Gallion, and C.-H. Moulin. 2013. Drawing together the knowledge of forestry and pastoralism experts in the construction of a technical support tool for silvopastoralism. Journal of Environmental Management 117:162-171. http://dx.doi.org/10.1016/j.jenvman.2012.12.041

Biagioli, M. 2009. Postdisciplinary liaisons: science studies and the humanities. Critical Inquiry 35(4):816-833. http://dx.doi. org/10.1086/599586

Bond, A., A. Morrison-Saunders, J. A. E. Gunn, J. Pope, and F. Retief. 2015. Managing uncertainty, ambiguity and ignorance in impact assessment by embedding evolutionary resilience, participatory modelling and adaptive management. Journal of Environmental Management 151:97-104. http://dx.doi.org/10.1016/ j.jenvman.2014.12.030

Brody, S. D., D. R. Godschalk, and R. J. Burby. 2003. Mandating citizen participation in plan making: six strategic planning choices. Journal of the American Planning Association 69(3):245264. http://dx.doi.org/10.1080/01944360308978018

Butler, C., and J. Adamowski. 2015. Empowering marginalized communities in water resources management: addressing inequitable practices in participatory model building. Journal of Environmental Management 153:153-162. http://dx.doi.org/10.1016/ j.jenvman.2015.02.010

Caves, J. K., G. S. Bodner, K. Simms, L. A. Fisher, and T. Robertson. 2013. Integrating collaboration, adaptive management, and scenario-planning: experiences at Las Cienegas National Conservation Area. Ecology and Society 18(3):43. http://dx.doi. org/10.5751/es-05749-180343

Chess, C., and K. Purcell. 1999. Public participation and the environment: Do we know what works? Environmental Science \& Technology 33(16):2685-2692. http://dx.doi.org/10.1021/es980500g

Decker, D. J., A. B. Forstchen, E. F. Pomeranz, C. A. Smith, S. J. Riley, C. A. Jacobson, J. F. Organ, and G. R. Batcheller. 2015. Stakeholder engagement in wildlife management: Does the public trust doctrine imply limits? Journal of Wildlife Management 79 (2):174-179. http://dx.doi.org/10.1002/jwmg.809

Depoe, S. P., J. W. Delicath, and M.-F. A. Elsenbeer. 2004. Communication and public participation in environmental decision making. SUNY Press, Albany, New York, USA.

Endres, D. 2009. Science and public participation: an analysis of public scientific argument in the Yucca Mountain controversy. Environmental Communication 3(1):49-75. http://dx.doi. org/10.1080/17524030802704369

Freeman, R. E. 1983. Strategic management: a stakeholder approach. Cambridge University Press, New York, New York, USA.

Freeman, R. E. 1999. Divergent stakeholder theory. Academy of Management Review 24(2):233-236. http://dx.doi.org/10.5465/ amr.1999.1893932

Gopnik, M., C. Fieseler, L. Cantral, K. McClellan, L. Pendleton, and L. Crowder. 2012. Coming to the table: early stakeholder engagement in marine spatial planning. Marine Policy 36 (5):1139-1149. http://dx.doi.org/10.1016/j.marpol.2012.02.012

Grimble, R., and K. Wellard. 1997. Stakeholder methodologies in natural resource management: a review of principles, contexts, experiences and opportunities. Agricultural Systems 55(2):173193. http://dx.doi.org/10.1016/s0308-521x(97)00006-1 
Hamilton, J. D. 2003. Exploring technical and cultural appeals in strategic risk communication: the Fernald radium case. Risk Analysis 23(2):291-302. http://dx.doi.org/10.1111/1539-6924.00309

Hood, N. E., T. Brewer, R. Jackson, and M. E. Wewers. 2010. Survey of community engagement in NIH-funded research. Clinical and Translational Science 3(1):19-22. http://dx.doi. org/10.1111/j.1752-8062.2010.00179.x

Innes, J. E., and D. E. Booher. 2004. Reframing public participation: strategies for the 21st century. Planning Theory and Practice 5(4):419-436. http://dx.doi.org/10.1080/1464935042000293170

Johnson, T. L., J. M. Bielicki, R. S. Dodder, M. R. Hilliard, P. O. Kaplan, and C. A. Miller. 2012. Advancing sustainable bioenergy: evolving stakeholder interests and the relevance of research. Environmental Management 51(2):339-353. http://dx.doi.org/10.1007/ $\underline{\text { s00267-012-9884-8 }}$

Jones, T. M., and A. C. Wicks. 1999. Convergent stakeholder theory. Academy of Management Review 24(2):206-221.

Keen, M., and S. Mahanty. 2006. Learning in sustainable natural resource management: challenges and opportunities in the Pacific. Society and Natural Resources 19(6):497-513. http://dx. doi.org/10.1080/08941920600663896

Kellert, S. R., J. N. Mehta, S. A. Ebbin, and L. L. Lichtenfeld. 2000. Community natural resource management: promise, rhetoric, and reality. Society and Natural Resources 13(8):705715. http://dx.doi.org/10.1080/089419200750035575

Kemp, R., S. Parto, and R. B. Gibson. 2005. Governance for sustainable development: moving from theory to practice. International Journal of Sustainable Development 8(1/2):12-30. http://dx.doi.org/10.1504/ijsd.2005.007372

Kidd, S., and L. McGowan. 2013. Constructing a ladder of transnational partnership working in support of marine spatial planning: thoughts from the Irish Sea. Journal of Environmental Management 126:63-71. http://dx.doi.org/10.1016/j.jenvman.2013.03.025

Knapp, C. N., F. S. Chapin III, G. P. Kofinas, N. Fresco, C. Carothers, and A. Craver. 2014. Parks, people, and change: the importance of multistakeholder engagement in adaptation planning for conserved areas. Ecology and Society 19(4):16. http:// dx.doi.org/10.5751/es-06906-190416

Koontz, T. M., and C. W. Thomas. 2006. What do we know and need to know about the environmental outcomes of collaborative management? Public Administration Review 66:111-121. http:// dx.doi.org/10.1111/j.1540-6210.2006.00671.x

Korsgaard, M. A., D. M. Schweiger, and H. J. Sapienza. 1995. Building commitment, attachment, and trust in strategic decisionmaking teams: the role of procedural justice. Academy of Management Journal 38(1):60-84. http://dx.doi.org/10.2307/256728

Krasny, M. E., and J. Delia. 2014. Campus sustainability and natural area stewardship: student involvement in adaptive comanagement. Ecology and Society 19(3):27. http://dx.doi. org/10.5751/es-06787-190327

Lachapelle, P. R., S. F. McCool, and M. E. Patterson. 2003. Barriers to effective natural resource planning in a "messy" world. Society and Natural Resources 16(6):473-490. http://dx.doi. org/10.1080/08941920309151
Larson, S., T. G. Measham, and L. J. Williams. 2010. Remotely engaged? Towards a framework for monitoring the success of stakeholder engagement in remote regions. Journal of Environmental Planning and Management 53(7):827-845. http:// dx.doi.org/10.1080/09640568.2010.490050

Maak, T. 2007. Responsible leadership, stakeholder engagement, and the emergence of social capital. Journal of Business Ethics 74 (4):329-343. http://dx.doi.org/10.1007/s10551-007-9510-5

McLain, R. J., and R. G. Lee. 1996. Adaptive management: promises and pitfalls. Environmental Management 20(4):437-448. http://dx.doi.org/10.1007/bf01474647

Mitchell, R. K., B. R. Agle, and D. J. Wood. 1997. Toward a theory of stakeholder identification and salience: defining the principle of who and what really counts. Academy of Management Review 22(4):853-886.

Noland, J., and R. Phillips. 2010. Stakeholder engagement, discourse ethics and strategic management. International Journal of Management Reviews 12(1):39-49. http://dx.doi.org/10.1111/ j.1468-2370.2009.00279.x

O'Faircheallaigh, C. 2010. Public participation and environmental impact assessment: purposes, implications, and lessons for public policy making. Environmental Impact Assessment Review 30 (1):19-27.

O'Rourke, M., and S. J. Crowley. 2013. Philosophical intervention and cross-disciplinary science: the story of the Toolbox Project. Synthese 190(11):1937-1954. http://dx.doi.org/10.1007/s11229-012-0175y

Parkins, J. R., and R. E. Mitchell. 2005. Public participation as public debate: a deliberative turn in natural resource management. Society and Natural Resources 18(6):529-540. http://dx.doi.org/10.1080/08941920590947977

Partidário, M. R., W. R. Sheate, O. Bina, H. Byron, and B. Augusto. 2008. Sustainability assessment for agriculture scenarios in Europe's mountain areas: lessons from six study areas. Environmental Management 43(1):144-165. http://dx.doi.org/10.1007/ s00267-008-9206-3

Powell, M. C., and M. Colin. 2008. Meaningful citizen engagement in science and technology: What would it really take? Science Communication 30(1):126-136. http://dx.doi. org/10.1177/1075547008320520

Prell, C., K. Hubacek, and M. Reed. 2009. Stakeholder analysis and social network analysis in natural resource management. Society and Natural Resources 22(6):501-518. http://dx.doi. org/10.1080/08941920802199202

PytlikZillig, L. M., and A. J. Tomkins. 2011. Public engagement for informing science and technology policy: What do we know, what do we need to know, and how will we get there? Review of Policy Research 28(2):197-217. http://dx.doi.org/10.1111/ j.1541-1338.2011.00489.x

Reed, M. S. 2008. Stakeholder participation for environmental management: a literature review. Biological Conservation 141 (10):2417-2431. http://dx.doi.org/10.1016/j.biocon.2008.07.014 
Reed, M. S., A. Graves, N. Dandy, H. Posthumus, K. Hubacek, J. Morris, C. Prell, C. H. Quinn, and L. C. Stringer. 2009. Who's in and why? A typology of stakeholder analysis methods for natural resource management. Journal of Environmental Management 90(5):1933-1949. http://dx.doi.org/10.1016/j. jenvman.2009.01.001

Ritti, R. 1968. Work goals of scientists and engineers. Industrial Relations: A Journal of Economy and Society 7(2):118-131. http:// dx.doi.org/10.1111/j.1468-232x.1968.tb01068.x

Rowe, G., and L. J. Frewer. 2000. Public participation methods: a framework for evaluation. Science, Technology \& Human Values 25(1):3-29. http://dx.doi.org/10.1177/016224390002500101

Saloranta, T. M. 2001. Post-normal science and the global climate change issue. Climatic Change 50(4):395-404. http://dx.doi. org/10.1023/A:1010636822581

Sands, R. G., J. Stafford, and M. McClelland. 1990. "I Beg to Differ": conflict in the interdisciplinary team. Social Work in Health Care 14(3):55-72. http://dx.doi.org/10.1300/J010v14n03 04

Smith, P. D., and M. H. McDonough. 2001. Beyond public participation: fairness in natural resource decision making. Society and Natural Resources 14(3):239-249. http://dx.doi. org/10.1080/089419201750111056

Soste, L., Q. J. Wang, D. Robertson, R. Chaffe, S. Handley, and Y. Wei. 2015. Engendering stakeholder ownership in scenario planning. Technological Forecasting and Social Change 91(1):250263. http://dx.doi.org/10.1016/j.techfore.2014.03.002

Stringer, L. C., A. J. Dougill, E. Fraser, K. Hubacek, C. Prell, and M. S. Reed. 2006. Unpacking "participation" in the adaptive management of social-ecological systems: a critical review. Ecology and Society 11(2):39.

Tompkins, E. L., and W. N. Adger. 2004. Does adaptive management of natural resources enhance resilience to climate change? Ecology and Society 9(2):10.

Vigar, G., and P. Healey. 2002. Developing environmentally respectful policy programmes: five key principles. Journal of Environmental Planning and Management 45(4):517-532. http:// dx.doi.org/10.1080/09640560220143530

Wagenet, L. P., and M. J. Pfeffer. 2007. Organizing citizen engagement for democratic environmental planning. Society and Natural Resources 20(9):801-813. http://dx.doi.org/10.1080/089$\underline{41920701216578}$

Webler, T., H. Kastenholz, and O. Renn. 1995. Public participation in impact assessment: a social learning perspective. Environmental Impact Assessment Review 15(5):443-463. http:// dx.doi.org/10.1016/0195-9255(95)00043-e 